\title{
ANALISA TURUNNYA KUALITAS STERILISASI PADA ULTRAVIOLET WATER STERILIZER DI MT. DRAGONARIA DENGAN METODE FAULT TREE ANALYSIS
}

\author{
Aditya Arin Sasongko ${ }^{\mathrm{a}}$, Abdi Seno ${ }^{\mathrm{b}}$, Andy Wahyu Hermanto \\ ${ }^{a}$ Taruna Program Studi Teknika PIP Semarang \\ ${ }^{b}$ dan Dosen Program Studi Teknika PIP Semarang
}

\begin{abstract}
Ultraviolet water sterilizer is a long cylindrical device used for the sterilization of water into drinkable water. Ultraviolet water sterilizer has two main parts: an adapter and UV tubes. The adapter serves to drain ration electricity in accordance with the voltage and current required by ultraviolet water sterilizer. Tubes $U V$ is containing lamps germicides where light is equipment major unruk make the water drinkable and the water will flow along the ultraviolet rays, so that the water flowing in the tube is passed through the sterilization process with ultraviolet rays so that the water unfit for consumption. The problems that the authors take in this study are the factors that affect the declining quality of sterilization, the impact of what happens when the quality of sterilization decreased, and what efforts made to keep the quality of sterilization is not decreased.

The method used is the method of fault tree analysis, a method to find the root of the problem by using a fault tree and simple logic gates to help determine the basic problem. Fault tree analysis method consists of a top event, intermediate event, and basic event where all three events are interrelated to form the fault tree that can be seen cause and effect. Data collected through observation, interviews, and literature directly to the subject related to the factors, the impact, as well as the efforts of the decline in the sterilization process to the sterilizer in order to improve the quality of drinking water.

The cause of the decline to the sterilizer sterilization process in order to improve the quality of drinking water in MT. Dragonaria that dirty filters, dirty water tubes, and the dirty germicidal lamp or berdampaknya resulting in less fresh water, complaint against the company, as well as the ship operational cost is reduced. Therefore made some efforts to improve the quality of the results of sterilization including cleaning filters, cleaning water tubes, and also clean the germicidal lamp, as well as auxiliary engine checks periodically so that the quality of sterilization can be increased.
\end{abstract}

\section{Keywords: Steilizer, fault tree, many produced fresh water}

\section{PENDAHULUAN}

Air adalah salah satu sumber daya alam yang memiliki fungsi sangat penting bagi kehidupan makhluk hidup di muka bumi. Air merupakan komponen lingkungan hidup yang penting bagi kelangsungan hidup baik kehidupan manusia maupun makhluk hidup lainnya. Untuk melestarikan fungsi air perlu dilakukan pengelolaan kualitas air dan pengendalian pencemaran air secara bijaksana dengan memperhatikan kepentingan generasi sekarang dan mendatang serta keseimbangan ekologis.

Pengelolaan kualitas air adalah upaya pemeliharaan air sehingga tercapai kualitas air yang diinginkan sesuai peruntukannya untuk menjamin agar kualitas air tetap dalam kondisi alamiahnya.

Mutu air adalah kondisi kualitas air yang diukur dan atau diuji berdasarkan parameterparameter tertentu dan metoda tertentu berdasarkan peraturan perundang-undangan yang berlaku. (Permen No.82, 2001)

Upaya atau tindakan untuk memelihara air minum dengan tujuan sebagaimana dimaksud dalam Peraturan Pemerintah tersebut juga diaplikasikan dalam menunjang keberlangsungan pengoperasian kapal dari satu pelabuhan ke pelabuhan yang lain, sehingga kebutuhan akan air minum yang layak di atas kapal terpenuhi. 
Adapun di kapal MT Dragonaria untuk mendapatkan air minum disamping di-supply dari darat juga dengan sistem sterilisasi. Presentasi air minum yang didapat dari darat kurang lebih hanya $30 \%$, dan sisanya $70 \%$ didapat dari proses sterilisasi air minum pada ultraviolet (UV) sterilizer di atas kapal.

Pada tanggal 5 bulan Januari tahun 2015 dalam voyage $701 / 15$, tepatnya di laut China ketika akan berlabuh atau sandar di Maoming Port, ada perbedaan yang langsung berdampak kepada crew kapal MT. Dragonaria berkaitan dengan air minum yang dihasilkan oleh ultraviolet water sterilizer. Ketika mengetahui hasil yang diproduksi oleh ultraviolet water sterilizer mulai mengalami penurunan kualitas hasil produksi, maka pengoperasian alat ini diberhentikan sementara, karena dinilai air yang dihasilkan kurang layak. Beberapa dari crew merasakan air yang tidak layak untuk diminum, sehingga ketika sandar di Maoming Port, banyak diantara crew kapal membeli air mineral dalam kemasan.

Voyage yang sama, ketika membawa muatan dari Maoming menuju Haiphong Vietnam, ultraviolet water sterilizer kembali dioperasikan untuk mengetahui apakah masih menghasilkan air minum yang kurang layak atau tidak tanpa adanya perbaikan dan ketika air yang dihasilkan tetap terlihat keruh dan berbau, crew kapal harus berhemat air minum.

Sehubungan dengan kondisi permasalahan-permasalahan tersebut, maka penulis tertarik untuk melakukan sebuah penelitian dengan judul "Analisa turunnya kualitas sterilisasi pada ultraviolet water sterilizer".

\section{METODOLOGI PENELITIAN}

Metode yang digunakan penyusun untuk menganalisa data khususnya rumusan masalah termasuk tentang faktor-faktornya menggunakan metode kualitatif fault tree analysis (analisa pohon kesalahan) dimana dalam penulisan ini memaparkan semua kejadian atau peristiwa yang terjadi di kapal dan yang mungkin akan terjadi di atas kapal dengan identifikasi kemungkinan-kemungkinan yang mempengaruhi kinerja screw compressor.

Analisis pohon kegagalan merupakan analisis induktif yaitu suatu kejadian disebabkan oleh kejadian sebelumnya. Kejadian sebelumnya disebabkan oleh kejadian lain lebih lanjut, kegagalan komponen. Masing-masing kegagalan tersebut dianalisis lebih lanjut penyebabnya sehingga sampai pada kondisi kejadian dasar (basic event). Kemudian pada tahap cut set yaitu hasil yang diperoleh dari pengujian masing-masing intermediate event sampai basic event untuk memperoleh penyebab dari top event. Adapun langkahIangkah melakukan analisis secara terstruktur pada sistem Fault Tree Analysis, yaitu:

1. Mengidentifikasi kejadian / peristiwa terpenting dalam sistem (top level event).

Langkah pertama dalam analisis data dengan metode FTA ini dibutuhkan pemahaman tentang sistem dan pengetahuan tentang jenis-jenis kerusakan untuk mengidentifikasi akar permasalahan sistem. Pemahaman tentang sistem dilakukan dengan mempelajari semua informasi tentang sistem dan ruang lingkupnya.

2. Membuat pohon kesalahan.

Setelah permasalahan terpenting teridentifikasi, langkah berikutnya adalah menyusun urutan sebab akibat pohon kesalahan. Pembuatan pohon kesalahan dilakukan dengan menggunakan simbolsimbol. Standarisasi simbol-simbol tersebut diperlukan untuk komunikasi dan kekonsistenan pohon kesalahan.

3. Menganalisis pohon kesalahan.

Analisis terhadap pohon kesalahan diperlukan untuk memperoleh informasi yang jelas dari suatu sistem, yaitu untuk mendapatkan faktor akar permasalahan dan perbaikan-perbaikan apa yang harus dilakukan pada sistem.

\section{HASIL DAN DISKUSI}

\section{Faktor-faktor apakah yang menyebab- kan turunnya kualitas sterilisasi Ultraviolet Water Sterilizer?}

\section{a. Top Event}

Dalam penelitian ini bahwa didapati beberapa top event dari menurunnya kualitas sterilisasi Ultraviolet Water Sterilizer. Berikut adalah gambar diagram pohon kesalahan menurunnya kualitas sterilisasi Ultraviolet Water Sterilizer, akan dijelaskan beberapa 
Aditya Arin Sasongko $^{\mathrm{a}}$, Abdi Seno ${ }^{\mathrm{b}}$, Andy Wahyu Hermanto ${ }^{\mathrm{c}}$

penjelasan-penjelasan pada setiap faktorfaktor yang menyebabkan top event terjadi.



Gambar 4.8 Pohon kesalahan dari menurunnya Kualitas sterilisasi Ultraviolet Water Sterilizer

Sumber : Dokumen Pribadi

Keterangan:

$\mathrm{X}$ : Turunnya kualitas sterilisasi Ultraviolet Water Sterilizer

A : Kotornya Tabung Air

B : Kotornya Lampu Germisida

C : Kotornya Filter

b. Basic Event and Intermediate Event

Basic Event dan Intermediate Event merupakan faktor-faktor pendukung terjadinya Top Event, sehingga dalam bagan di bawah ini akan dijelaskan lebih rinci mengenai faktor apa saja yang menyebabkan Top Event terjadi, antara lain:

1) Kotornya Tabung Air

Kotornya tabung air selanjutnya disebut dengan Intermediate Event ini memiliki faktor lainnya sebagai penyebab dari kotornya tabung, dua faktor yang mempengaruhi sehingga disebut dengan Basic Event digambarkan dalam pohon kesalahan sebagai berikut:

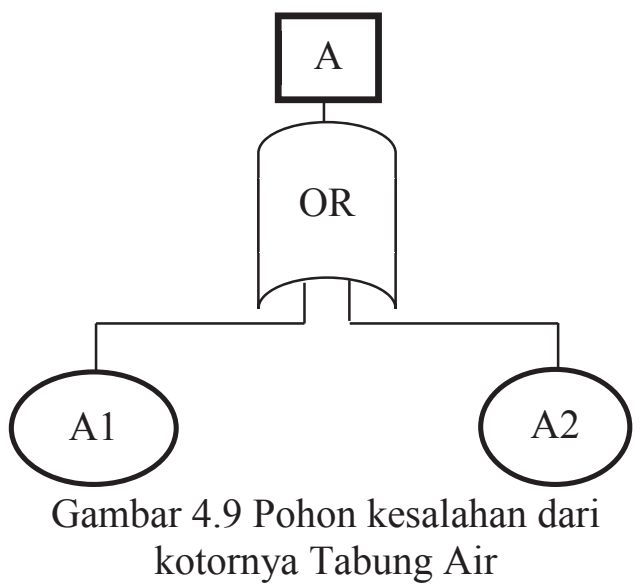

Sumber: Dokumen Pribadi

Keterangan:

A : Kotornya Tabung Air

A1: Kurangnya tekanan air yang masuk ke dalam UV filter

A2 : Tidak teraturnya pembersihan sterilizing Chamber

Kotornya tabung air yang terdapat pada sterilizer dapat menyebabkan menurunnya hasil produksi air yang telah tersterilisasi. Kotornya tabung air ini dapat dipengaruhi oleh beberapa faktor diantaranya:

a) Kurangnya tekanan air yang masuk kedalam UV Sterilizer karena tekanan air yang sesuai dapat menguraikan kotoran-kotoran bakteria serta kuman yang terkandung dalam air sehingga sterilisasi bekerja optimal. Normalnya tekanan $6 \mathrm{~kg} / \mathrm{cm}^{2}$ atau 6 bar. Besarnya nilai tekanan dapat dibaca pada pressure gauge di sterilizer.

b) Tidak teraturnya pembersihan sterilizing chamber atau tabung air dimana didalamnya terdapat batu-batu dolomite yang berperan sebagai penetral air dan penyaring kotoran, kuman dan bakteri. Pembersihan batubatu dolomite dari lumpur-lumpur yang menghambat proses sterilisasi wajib dilakukan serta penambahan batu-batu dolomite apabila batu tersebut mulai terkikis dan berkurang. 
Hal tersebut dapat meningkatkan dan mengoptimalkan hasil sterilisasi.

Dari data di atas dapat ditarik persamaan bolean.

$$
\mathrm{A}=\mathrm{A} 1+\mathrm{A} 2
$$

Hasil analisa kualitatif yang diadapat dari analisa proses kualitas sterilisasi Ultraviolet Water Sterilizer dengan top event yaitu Kotornya Tabung Air, didapat beberapa hasil dari penjabaran yang dilakukan seperti penjelasan di atas, yaitu:

\section{A : Kotornya Tabung Air}

A1: Kurangnya tekanan air yang masuk ke dalam UV Sterilizer

A2: Tidak teraturnya pembersihan sterilizing Chamber

\section{2) Kotornya Lampu Germisida}

Kotornya permukaan lampu germisida ini dapat mempengaruhi proses sterilisasi karena fungsi utama dari lampu ini yaitu mencegah berkembangnya kuman dan bakteri dengan cara penyinaran sinar ultraviolet Apabila lampu ini kotor maka akan mengganggu penyinaran yang dapat mengurangi panjang gelombang kurang dari 253,7 mm maka kuman dan bakteri akan berkembang karena dengan panjang gelombang yang kurang dari $253,7 \mathrm{~mm}$ kuman dan bakteri tidak akan mati.

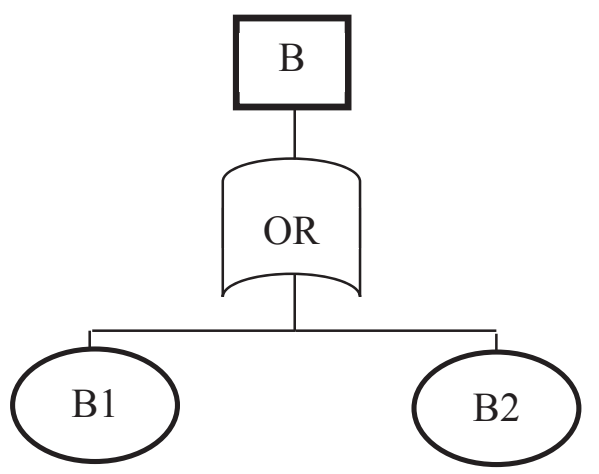

Gambar 4.10 Pohon kesalahan dari kotornya lampu germisida

Sumber : Dokumen Pribadi

Keterangan:

B : Kotornya lampu germisida
B1 : Adanya lumut yang menempel pada dinding lampu

B2 : Tidak teraturnya pembersihan lampu Germisida

Kotornya lampu germisida yang terdapat pada sterilizer dapat menyebabkan menurunnya hasil produksi air yang telah tersterilisasi. Kotornya lampu germisida ini dapat dipengaruhi oleh beberapa faktor diantaranya:

a) Menempelnya kotoran seperti lumut atau microorganism yang dapat berkembang biak pada dinding lampu germisida dengan bahan dasar kaca, sehingga lumut ini menghalangi proses keluarnya sinar UV secara maksimal

b) Tidak teraturnya pembersihan lampu germisida. Pengecekan secara berkala pada alat utama sterilizer ini sangat diperlukan, karena jika tidak dibersihkan atau dicek setiap waktu dengan tingkat rutinitas kurang lebih 3 kali dalam satu minggu maka lumut atau kotoran yang lainnya akan sangat cepat bertumbuh pada dinding lampu germisida ini. Keteraturan pengecekan sangat berpengaruh karena ini merupakan bagian dari perawatan daripada melakukan penggantian lampu yang kurang efisien. Waktu yang tepat untuk melaksanakan pembersihan ini adalah ketika UV sterilisasi tidak sedang dioperasikan.

Dari data di atas dapat ditarik persamaan bolean.

$$
\mathrm{B}=\mathrm{B} 1+\mathrm{B} 2
$$

Hasil analisa kualitatif yang diadapat dari analisa proses kualitas sterilisasi Ultraviolet Water Sterilizer dengan top event yaitu kotornya lampu germisida, didapat beberapa hasil dari penjabaran yang dilakukan seperti penjelasan di atas, yaitu:

B : Kotornya lampu germisida

B1: Terdapat lumut yang menempel

B2: Tidak teraturnya pembersihan lampu germisida 
Aditya Arin Sasongko $^{\mathrm{a}}$, Abdi Seno ${ }^{\mathrm{b}}$, Andy Wahyu Hermanto ${ }^{\mathrm{c}}$

3) Kotornya Filter

Menurut informasi yang diperoleh dari masinis IV, kotornya filter disebabkan karena adanya kuman dan bakteri yang menempel pada filter. Kuman dan bakteri tersebut bersumber dari air yang diolah pada UV sterilizer, biasanya kuman dan bakteri tersebut menempel pada dinding-dinding filter yang menyebabkan filter tersebut menjadi kotor sehingga berdampak pada tertutupnya lubang-lubang filter yang mengakibatkan menurunnya hasil produksi UV Sterilizer.

Di MT. Dragonaria filter tersebut banyak ditemukan kuman dan bakteri dikarenakan kotornya kualitas air yang masuk dalam UV Sterilizer. Hal itu disebabkan karena kapal berlayar di perairan yang memiliki kualitas air laut yang buruk. Pada kenyataannya tidak ada kaitan langsung pada power sterilizer meskipun begitu bahwa bakteri dan kuman selalu berkumpul pada filter dan akan dilakukan penggantian setidaknya 1 bulan sekali supaya air yang di produksi selalu bersih.

Pada Filtermass dapat dibersihkan 3 bulan sekali supaya tidak banyak lumpur yang mengendap pada UV Steirilizer agar proses sterilisasi berjalan dengan normal karena pengendapan lumpur menyebabkan menurunnya hasil produksi air minum.

Kurangnya perawatan filter pada $U V$ Sterilizer akan menyebabkan tiga faktor yang mempengaruhi terjadinya kotornya filter. Faktor yang mempengaruhi ini saling berkaitan satu sama lain sehingga ketika satu saja faktor terjadi maka akan tetap mengalami kotornya filter ini. Faktor tersebut digambarkan dalam fault tree sederhana di bawah ini sebagai berikut:

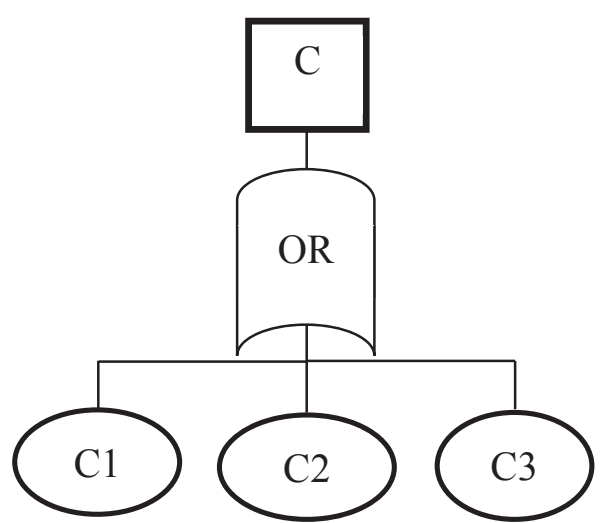

Gambar 4.11 Pohon kesalahan dari kotornya filter

Sumber : Dokumen Pribadi

Keterangan :

C : Kotornya Filter

$\mathrm{C} 1$ : Kondisi air yang kurang bersih

C2: Kotornya Fresh Water Tank

C3: Tidak optimalnya kinerja FWG.

Penjabaran pohon kesalahan dari intermediate event yang pertama adalah kotornya Filter. Kondisi pada Filter sangat mempengaruhi proses sterilisasi air minum. Kotornya filter sendiri dipengaruhi oleh tiga hal yang disebut dengan basic event yang akan dijabarkan di bawah ini.

a) Kondisi air yang kurang bersih

Masalah air bersih merupakan hal yang sangat penting bagi kehidupan manusia dimana setiap hari kita membutuhkan air bersih untuk minum. Menurut Effendi (2003), kualitas air bersih dapat ditinjau dari segi fisik, kimia, dan biologi. Kualitas fisik ditinjau dari bau, rasa, dan warna. Kualitas kimia dapat diteliti melalui pengamatan tentang kesadahan, $\mathrm{pH}$, kandungan ion dan sebagainya. Sedangkan ada atau tidaknya mikroorganisme penyebab penyakit pada air merupakan syarat biologi air bersih. Kondisi ini merupakan indikator-indikator kelayakan air yang layak untuk dikonsumsi.

Selain dari segi kualitas, jumlah air juga harus memadai dalam rangka 
pemenuhan kebutuhan manusia. Kualitas air yang digunakan masyarakat harus memenuhi syarat kesehatan agar dapat terhindar dari berbagai penyakit maupun gangguan kesehatan yang dapat disebabkan oleh air. Untuk mengetahui kualitas air tersebut, perlu dilakukan pemeriksaan laboratorium yang mencakup antara lain pemeriksaan bakteriologi air, meliputi Most Protable Number (MPN) dan angka kuman. Pemeriksaan MPN dilakukan untuk pemeriksaan kualitas air minum, air bersih, air badan, air pemandian umum, air kolam renang dan pemeriksaan angka kuman pada air PDAM. Khusus air minum disyaratkan bahwa tidak mengandung bakteri patogen, misalnya bakteri golongan E. coli, salmonella typhi, vibriocholera, kuman-kuman ini mudah tersebar melalui air (Transmitted by water) dan tidak mengandung bakteri non-patogen, seperti Actinomycetes dan Cladocera. Persyaratan air minum secara Bakteriologis.

b) Kotornya Fresh Water Tank

Pada tangki air tawar yang kurang perawatan secara teratur juga dapat mengakibatkan filter lebih cepat kotor sebelum waktu pergantian filter yang seharusnya diganti kurang lebih sebulan sekali, ini terjadi karena banyaknya endapan-endapan pada tangki air tawar. Endapan-endapan ini bisa terjadi karena pengaratan pada dasar tangki karena air dari hasil fresh water generator memiliki kadar garam yang tinggi.

c) Tidak optimalnya kinerja FWG

Fresh water generator, merupakan salah satu pesawat bantu yang sangat penting di atas kapal, hal ini dikarenakan dengan menggunakan FWG dapat menghasilkan air tawar yang dapat digunakan untuk minum, memasak, mencuci dan bahkan menjalankan mesin penting lainnya yang menggunakan air tawar sebagai media pendingin. Pada FWG air tawar umumnya dihasilkan menggunakan metode evaporasi. Jadi air tawar tersebut dihasilkan oleh penguapan air laut dengan menggunakan panas dari salah satu sumber panas.

Umumnya sumber panas yang tersedia diambil dari water jacket mesin utama, yang digunakan untuk mendinginkan komponen mesin utama seperti kepala silinder, liner dan lain-lain, suhu yang dihasilkan dari water jacket sekitar $70^{\circ} \mathrm{C}$. Tetapi pada suhu ini penguapan air tidak maksimal, seperti yang kita ketahui bahwa penguapan air terjadi pada $100^{\circ} \mathrm{C}$ dibawah tekanan atmosfer. Jadi dalam rangka untuk menghasilkan air bersih di $70^{\circ} \mathrm{C}$ kita perlu mengurangi tekanan atmosfer, yang dilakukan dengan menciptakan vakum di dalam ruang dimana penguapan berlangsung. Juga, sebagai akibat vakum pendinginan air laut menguap pada suhu yang lebih rendah, Air akan di dinginkan dan dikumpulkan kemudian dipindahkan ke tangki.

Tidak optimalnya kinerja FWG yang menyebabkan menurunnya hasil produksi air tawar diketahui oleh terganggunya sistem antara lain:

Terdapat kerak-kerak di bagian luar pipa evaporator sehingga penyerahan panas tidak sempurna pada pipa-pipa pemanas sering kali terjadi pembenukan kerak-kerak yang terjadi di luar pipa yaitu pada sisi air laut, air laut akan mendidih dan menguap di luar sisi air pemanas dan mengakibatkan air laut banyak yang menempel pada pipa-pipa tersebut lama kelamaan akan timbul kerakkerak di bagian luar pipa dan akan menyebabkan berkurangnya kemampuan evaporator untuk menghasilkan uap.

Terjadinya over load, terjadi pada motor sehingga motor berhenti bekerja atau shut down akibat beban berlebihan srhingga kegiatan supply air laut terhenti. Terdapat udara dalam 
Aditya Arin Sasongko $^{\mathrm{a}}$, Abdi Seno ${ }^{\mathrm{b}}$, Andy Wahyu Hermanto ${ }^{\mathrm{c}}$

sistem, udara masuk pada bagian hisap pompa sehingga dapat menghambat sirkulasi air akibat adanya udara sebagai penghalang.

Dari hasil pengamatan di atas menyimpulkan jika hal itu terjadi maka akan mempengaruhi hasil air yang dihasilkan fresh water generator dari kandungan garam meninggi, produksi air kurang optimal serta kotornya air karena kerak dari fresh water generator yang terbawa menuju ke tangki air tawar. Air dari tangki tersebut yang akan digunakan pada sterilizer dan secara tidak langsung apabila kualitas air tersebut kotor dan mengandung kerak akan mempercepat kotornya filter pada sterilizer.

Dari data di atas dapat ditarik persamaan bolean

$$
\mathrm{C}=\mathrm{C} 1+\mathrm{C} 2+\mathrm{C} 3
$$

Hasil analisa kualitatif yang didapat dari analisa menurunnya kualitas proses sterilisasi pada ultraviolet water sterilizer dengan top event kotornya filter, didapat beberapa hasil dari penjabaran yang dilakukan seperti penjelasan di atas, yaitu:

C : Kotornya Filter

C1: Kondisi air yang kurang bersih

C2 : Kotornya Fresh Water Tank

C3: Tidak optimalnya kinerja FWG.

c. Cut Set

Hasil penelitian yang diperoleh dari pengujian masing-masing intermediate event sampai basic event untuk memperoleh penyebab dari top event adalah sebagai berikut:

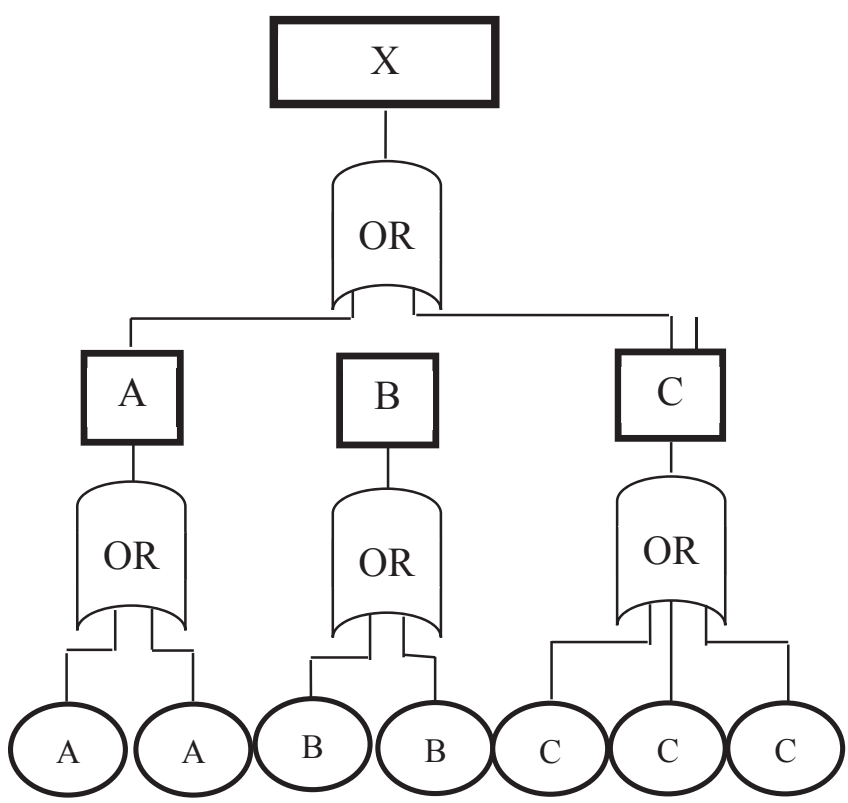

Gambar 4.12 Fault tree menurunnya proses sterilisasi

Sumber : Dokumen pribadi

Keterangan :

$\mathrm{X}$ : Turunnya kualitas sterilisasi Ultraviolet Water Sterilizer

A : Kotornya Tabung Air

A1: Kurangnya tekanan air yang masuk kedalam UV filter

A2: Tidak teraturnya pembersihan sterilizing chamber

B : Kotornya lampu germisida

B1: Adanya lumut yang menempel

B2: Tidak teraturnya pembersihan lampu germisida

C : Kotornya Filter

$\mathrm{C} 1$ : Kondisi air yang kurang bersih

C2: Kotornya Fresh Water Tank

C3: Tidak optimalnya kinerja FWG

Dari top event $\mathrm{X}$ : turunnya kualitas sterilisasi Ultraviolet Water Sterilizer, disebabkan oleh beberapa faktor menjadi intermediate event A: kotornya tabung air, yang disebabkan oleh basic event A1: kurangnya tekanan air yang masuk ke dalam UV filter, dan basic event A2: tidak teraturnya pembersihan sterilizing chamber. Kemudian top event $\mathrm{X}$ juga dipengaruhi oleh intermediate event $\mathrm{B}$ : kotornya lampu germisida yang dipengaruhi oleh basic event B1: adanya 
lumut yang menempel dan B2: Tidak teraturnya pembersihan lampu germisida. Terakhir top event $\mathrm{X}$ juga dipengaruhi oleh intermediate event $\mathrm{C}$ : kotornya filter, yang disebabkan oleh basic event $\mathrm{C} 1$ : kondisi air yang kurang bersih, $\mathrm{C} 2$ : kotornya fresh water tank, dan juga dipengaruhi oleh $\mathrm{C} 3$ : tidak optimalnya kinerja FWG.

Masing-masing event tersebut telah dilakukan penjabaran serta pembahasan yang komprehensif dengan menggunakan metode fault tree analysis atau analisa pohon kesalahan untuk membahasnya berikut ini adalah tabel kebenaran dari permasalahan utama.

Jadi dari pembahasan yang dilakukan dan dilihat dari tabel kebenaran di atas, dapat ditarik sebuah kesimpulan dari penyebab menurunnya proses kualitas sterilisasi Ultraviolet Water Sterilizer di MT. Dragonaria dengan persamaan bolean adalah sebagai berikut:

$$
\begin{aligned}
& \mathrm{X}=\mathrm{A}+\mathrm{B}+\mathrm{C} \\
& \mathrm{A}=\mathrm{A} 1+\mathrm{A} 2 \\
& \mathrm{~B}=\mathrm{B} 1+\mathrm{B} 2 \\
& \mathrm{C}=\mathrm{C} 1+\mathrm{C} 2+\mathrm{C} 3
\end{aligned}
$$

Sehingga menghasilkan Cut Set

$$
\begin{aligned}
\mathrm{X}= & {[\mathrm{A} 1+\mathrm{A} 2]+[\mathrm{B} 1+\mathrm{B} 2]+[\mathrm{C} 1+\mathrm{C} 2} \\
& +\mathrm{C} 3] \\
\mathrm{X}= & \mathrm{A} 1+\mathrm{A} 2+\mathrm{B} 1+\mathrm{B} 2+\mathrm{C} 1+\mathrm{C} 2+\mathrm{C} 3
\end{aligned}
$$

Dari data di atas, diperoleh penyebab terbesar menurunnya proses kualitas sterilisasi pada Ultraviolet Water Sterilizer di MT. Dragonaria yaitu kotornya lampu germisida dengan persentase $39.13 \%$ kemudian kotornya tabung air dengan persentase $30.43 \%$ dan yang paling kecil adalah kotornya filter dengan persentase $30.42 \%$.

\section{Dampak apa yang terjadi ketika kualitas sterilisasi Ultraviolet Water Sterilizer menurun?}

Dengan melakukan observasi dan melihat keadaan yang terjadi terhadap proses sterilisasi air minum di atas kapal MT. Dragonaria dan juga berdasarakan hasil wawancara terhadap Masinis 1, Masinis 2, Masinis 3, dan Masinis 4, termasuk review engine log book mengenai perawatan dan perbaikan tentang mesin bantu ini yang dilihat dari kegiatan treatment mengenai pengetesan $\mathrm{pH}$ menghasilkan rangkuman kesimpulan yang berbeda-beda mengenai dampak yang dirasakan, terdapat tiga dampak yang dirasakan yaitu:

a. Air yang diminum kurang segar. Dampak ini dirasakan langsung oleh semua crew yang bekerja pada MT. Dragonaria, dengan melihat secara fisik warna yang keruh dan berbuih. Rasa dan warna yang berubah menjadi air yang tidak layak membuat para crew menjadi tidak ingin meminum air hasil sterilisasi ini walaupun air tersebut sudah dimasak kembali. Air yang diproduksi ini bersifat asam dengan nilai $\mathrm{pH} 10$, sedangkan air yang baik dan layak untuk diminum tidak bersifat asam maupun basa melainkan bersifat netral dengan nilai $\mathrm{Ph}$ 7. Keasaman air produksi dari mesin bantu ini juga menimbulkan bau yang tidak sedap, buih yang terlalu banyak. Dampak ini merupakan dampak yang bisa dilihat dan dirasakan secara langsung.

b. Menjadi hal yang sangat serius apabila kebutuhan akan air minum tidak terpenuhi oleh karena itu kapten kapal langsung mengambil keputusan untuk membuat complaint terhadap perusahaan. Ini merupakan dampak secara tidak langsung dari crew kepada perusahaan dikarenakan asupan untuk air minum yang layak tidak segera diberikan. Surat ini dilayangkan kepada perusahaan setelah melakukan beberapa perbaikan dan perawatan terhadap mesin bantu ultraviolet water sterilizer, namun tidak membuahkan hasil. Surat ini dibuat oleh kapten kapal melalui rekomendasi yang diberikan oleh chief engineer sebagai penanggung jawab terhadap permesinan yang berada di atas kapal, surat yang dikirim kepada perusahaan telah melalui prosedur yang tepat yaitu permintaan atau request untuk permesinan yang tidak bekerja optimal harus dilakukan perbaikan dan perawatan terlebih dahulu sebelum mengajukan complaint. 
Aditya Arin Sasongko $^{\mathrm{a}}$, Abdi Seno ${ }^{\mathrm{b}}$, Andy Wahyu Hermanto ${ }^{\mathrm{c}}$

c. Ship Operational Cost berkurang karena crew harus membeli air minum dalam kemasan dari darat dengan uang operasi kapal. Kebutuhan akan air minum ini ditindaklanjuti sementara dengan memanfaatkan uang operasi kapal yang seharusnya diperuntukkan untuk membayar beberapa orang yang ditunjuk membantu kapal ketika akan sandar, namun uang ini digunakan untuk membeli kebutuhan air minum dalam kemasan sebanyak 50 kardus. Sehingga uang operasional kapal menjadi berkurang. Bahkan chief engineer membeli sendiri air minum dalam kemasan tersebut untuk kebutuhan di engine control room. Uang untuk operasi kapal ini juga dilaporkan kepada perusahaan untuk dokumentasi dan catatan mengenai pengeluaran di luar biaya pokok.

d. Dampak dari setiap basic event yang dijabarkan di atas adalah sebagai berikut:

1) Kurangnya tekanan air yang masuk kedalam UV filter mengakibatkan air yang masuk yang masih membawa kotoran akan berkumpul di-filter

2) Tidak teraturnya pembersihan sterilizing chamber mengakibatkan tumpukan kotoran yang bersatu sebelum proses filterisasi

3) Adanya lumut yang menempel pada dinding lampu germisida mengakibatkan sterilisasi sinar UV tidak maksimal

4) Tidak teraturnya pembersihan lampu grmisida mengakibatkan tumbuhnya banyak lumut di sekitar lampu germisida

5) Kondisi air yang kurang bersih mengakibatkan hasil air yang di produksi kurang maksimal

6) Kondisi Fresh Water Tank yang biasanya terdapat banyak sekali kotoran mengakibatkan air yang akan disterilkan menjadi tidak bersih

7) Tidak optimalnya kinerja FWG mengakibatkan ke-higienis-an air yang berasal dari FWG masih terdapat kandungan-kandungan garam sisa

\section{Bagaimana upaya mengatasi menurunnya proses sterilisasi pada sterilizer?}

Berdasarkan observasi atau penelitian yang penulis lakukan, dan wawancara dengan Masinis 1, Masinis 2, Masinis 3, dan Masinis 4 juga studi pustaka dari hasil pengamatan yang dilihat dari Engine Log Book pada tahun 2013-2014 tentang upaya apa yang dilakukan ketika kualitas proses sterilisasi mengalami penurunan yaitu:

a. Membersihkan lampu germisida, yang merupakan alat untuk menyeterilkan air dari bakteri yang menjadikan air tidak layak untuk dikonsumsi. Pembersihan ini diharapkan dilaksanakan secara rutin dan terjadwal karena kegiatan pembersihan lampu germisida paling berpengaruh terhadap kualitas hasil produksi air ini. Ketika lampu germisida dibersihkan juga harus memperhatikan kain atau majun yang bersih sehingga lampu tidak mengalami goresan yang mengakibatkan arah sinar UV mengalami perubahan.

b. Membersihkan tabung air, sebagai penampung air sebelum masuk ke Ultraviolet Water Sterilizer. Tabung air merupakan tempat penyimpanan air sebelum memasuki pesawat bantu ultraviolet water sterilizer sehingga kehigienis-an perlu dijaga dari kotorankotoran yang menempel pada dinding tabung air yang didalamnya juga terdapat filtermass. Kegiatan pembersihan tabung air ini juga harus dilaksanakan secara rutin maksimal setiap satu bulan 2 kali sehingga dengan melakukan pembersihan terhadap tabung air ini kita bisa mengontrol dan melihat keadaan dari tabung tersebut dan mengambil apakah harus diadakan pembersihan atau tidak.

c. Membersihkan filter yang berfungsi menyaring kotoran yang terlihat atau tampak. Filter ini adalah saringan terakhir sebelum air minum dinetralkan atau disterilisasi, sehingga peran filter disini sangat berpengaruh. Saringan ini perlu dilakukan pembersihan yang terjadwal dan rutin karena sangat 
mempengaruhi hasil kualitas proses sterilisasi. Filter yang dimaksud juga harus diadakan pergantian dengan sparepart yang baru secara rutin karena saringan ini jika sudah ada kotoran yang mengendap karena keterlambatan pembersihan tidak bisa dibersihkan lagi sampai bersih. Sehingga penggantian saringan diperlukan. Akan tetapi untuk menghemat bisa dilakukan pembersihan 2 atau 3 hari sekali sehingga saringan ini bisa dimanfaatkan selama mungkin.

d. Pengecekan berkala pada alat dan hasil produksi. Pengecekan ini sebaiknya maksimal 3 hari sekali agar hasil yang diinginkan dapat terwujud. Pengecekan ini diharapkan dilaksanakan dengan sungguh-sungguh dan memperhatikan beberapa kondisi keadaan mesin bantu. Pengecekan terhadap hasil produksi dan tekanan air yang masuk harus dicatat dan dievaluasi setiap minggu sehingga melalui kegiatan pengecekan ini dapat dilihat apakah mesin bantu ultraviolet water sterilizer dalam keadaan baik atau tidak. Atau bahkan harus dilakukan perbaikan dengan segera.

Setelah melakukan observasi, meganalisa masalah, dan melakukan upaya-upaya yang dilaksanakan untuk memperbaiki dan merawat equipment maka penulis dapat menyimpulkan bahwasannya proses kualitas Ultraviolet Water sterilizer dapat berjalan dengan baik sesuai dengan yang diharapkan.

\section{KESIMPULAN}

Berdasarkan hasil penelitian, analisis data, dan pembahasan permasalahan yang telah diuraikan dan dibahas pada bab sebelumnya, tentang "Analisa turunnya kualitas sterilisasi pada Ultraviolet Water Sterilizer di MT. Dragonaria dengan metode Fault Tree Analysis", maka penulis dapat mengambil kesimpulan sebagai berikut:

1. Faktor yang menyebabkan menurunnya kualitas sterilisasi pada Ultraviolet Water Sterilizer adalah:

a. Kotornya tabung air yang tidak dibersihkan secara teratur dan terjadwal. b. Kotornya lampu germisida yang menjadi alat utama sterilisasi dapat bekerja dengan baik.

c. Kotornya filter atau saringan yang menyaring kotoran dari air yang akan masuk kedalam.

Dengan kesimpulan yang menggunakan persamaan Bolean

$$
\mathrm{X}=\mathrm{A} 1+\mathrm{A} 2+\mathrm{B}+\mathrm{C} 1+\mathrm{C} 2+\mathrm{C} 3
$$

2. Dampak yang terjadi akibat menurunnya kualitas sterilisasi pada Ultraviolet Water Sterilizer yaitu:

a. Air yang diminum kurang segar dan menjadi air minum yang tidak layak dikonsumsi.

b. Complaint terhadap perusahaan karena pemenuhan akan air minum yang layak tidak segera dipenuhi.

c. Ship operational cost berkurang untuk membeli air mineral dari darat.

3. Upaya yang dilakukan untuk mengatasi turunnya kualitas sterilisasi pada Ultraviolet Water Sterilizer adalah:

a. Membersihkan lampu germisida, yang merupakan alat untuk menyeterilkan air dari bakteri yang menjadikan air tidak layak untuk dikonsumsi

b. Membersihkan tabung air, sebagai penampung air sebelum masuk ke Ultraviolet Sterilization

c. Membersihkan filter yang berfungsi menyaring kotoran yang terlihat atau tampak

d. Pengecekan berkala pada alat dan hasil produksi

\section{DAFTAR PUSTAKA}

Effendi, Hefni. 2003. Telaah Kualitas Air Bersih. Jakarta: Kanisius

Engine Log Book Maintenance of Ultraviolet Water Sterilizer JSA - 3000

Horne, M. Mima. 2008. Keseimbangan Cairan Elektrolit \& Asam Basa. Jakarta

Instruction Manual Book of Ultraviolet Water Sterilizer JSA - 3000

Kristiansen, Svein. 2005. Maritime Transportation Safety Management and Risk Analysis. New York 
Analisa Turunnya Kualitas Sterilisasi Pada Ultraviolet Water Sterilizer di MT. Dragonaria dengan Metode Fault Tree Analysis

Aditya Arin Sasongko $^{\mathrm{a}}$, Abdi Seno ${ }^{\mathrm{b}}$, Andy Wahyu Hermanto $^{\mathrm{c}}$

Peraturan Pemerintah Nomor 82 Tahun 2001

Peraturan Menteri Kesehatan RI Nomor 173/Men.Kes/per/VII/1997

Rustiawan, Dede. 2010. Praktis Belajar Fisika. Jakarta : Visindo

Sugiyono. 2009. Metode Penelitian Kuantitatif Kualitatif dan $R \& D$. Bandung: Alfabeta
Suripin. 2002. Pelestarian Sumber Daya Tanah dan Air. Yogyakarta

Swain, Helen. 2008. Prinsip-prinsip Sains Untuk Keperawatan. Jakarta: Erlangga 